\title{
Controle da cochonilha-parda Parthenolecanium persicae (Fabricius, 1776) (Hemiptera: Coccidae) na cultura da videira
}

\author{
Control of the european peach scale Parthenolecanium persicae (Fabricius, 1776) \\ (Hemiptera: Coccidae) in vineyards
}

\author{
Ana Paula Schneid Afonso ${ }^{1}$ Ivonel Teixeira ${ }^{2}$ Marcos Botton $^{3}$ \\ João Luiz Faria ${ }^{4}$ Alci Enimar Loeck ${ }^{5}$
}

\section{RESUMO}

A cochonilha-parda Parthenolecanium persicae é considerada uma das principais pragas da videira na região sul do Brasil. Com o objetivo de avaliar inseticidas fosforados e neonicotinóides foram conduzidos dois experimentos avaliandose os produtos fitossanitários: dimetoato (Tiomet $400 \mathrm{CE}, 100 \mathrm{~mL}$ $100 \mathrm{~L}$ de água ${ }^{-1}$ ), fenitrotion (Sumithion $500 \mathrm{CE}, 150 \mathrm{~mL} 100 \mathrm{~L}$ de água ${ }^{-1}$ ), metidation (Supracid 400CE, 100mL 100L de água ${ }^{-1}$, paratiom metil (Folidol 600 CE, 100mL 100L de água ${ }^{-1}$ ) e triclorfon (Dipterex 500 SNAqC, 300mL 100L de água ${ }^{-1}$ ) em 2001 e, imidacloprid (Provado $200 \mathrm{SC}, 30,40$ e $50 \mathrm{~mL} 100 \mathrm{~L}$ de água ${ }^{-1}$ ), tiacloprid (Calypso $480 \mathrm{SC}, 20,30$ e 40mL $100 \mathrm{~L}^{-1}$ ), tiametoxam (Actara $250 \mathrm{WG}, 20,30$ e 40g $100 \mathrm{~L}$ de água ${ }^{-1}$ ) e paratiom metil (Folidol $600 \mathrm{CE}, 100 \mathrm{~mL} 100 \mathrm{~L}^{-1}$ ) em 2002. Os produtos foram

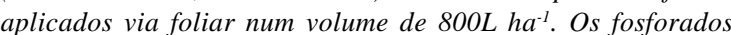
fenitrotion, metidation, paratiom metil e os neonicotinóides imidacloprid e tiametoxam foram eficientes no controle de ninfas do terceiro ínstar de $\boldsymbol{P}$. persicae. Os inseticidas dimetoato e tiacloprid não atingiram $50 \%$ de controle da cochonilha-parda na cultura da videira.

Palavras-chave:controle químico, neonicotinóides, Vitis spp., fosforados.

\section{ABSTRACT}

The european peach scale Parthenolecanium persicae is one of the most important grape pest in southern Brasil. The insecticides dimetoato (Tiomet $400 \mathrm{CE}, 100 \mathrm{~mL} 100 \mathrm{~L}^{-1}$ ), fenitrotion (Sumithion $500 \mathrm{CE}, 150 \mathrm{~mL} 100 \mathrm{~L}^{-1}$ ), metidation (Supracid 400 CE, 100mL/100L), paratiom metil (Folidol 600 CE,

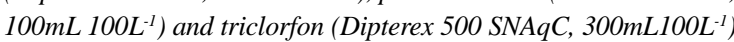

were evaluated in a field experiment in 2001 and imidacloprid (Provado 200 SC, 30, 40 and 50mL 100L ${ }^{-1}$ ), tiacloprid (Calypso $480 \mathrm{SC}, 20,30$ and $40 \mathrm{~mL} 100 \mathrm{~L}^{-1}$ ), tiametoxam (Actara $250 \mathrm{WG}$

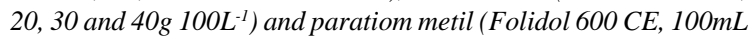
$100 \mathrm{~L}^{-1}$ ) in 2002. Insecticides were sprayed using $800 \mathrm{~L}$ of water ha ${ }^{I}$ seeking third instar nymphs. Phosporous insecticides fenitrotion, metidation, paratiom metil and triclorfon and the neonicotinoid imidacloprid and tiametoxam were efficient for $\boldsymbol{P}$. persicae control. Dimetoato and tiacloprid were not efficient for insect control reducing pest population in levels bellow $50 \%$.

Key words: chemicalcontrol, neonicotinoid, Vitis sp, organophosphorus.

\section{INTRODUÇÃO}

Duas espécies de Coccidae do gênero Parthenolecanium são consideradas pragas da videira, sendo conhecidos Parthenolecanium persicae (Fabricius, 1776) e Parthenolecanium corni (Bouché, 1844) (Hemiptera: Coccidae) (GONZÁLEZ, 1983; PELLIZZARI, 1997). Devido à similaridade morfológica e, muitas vezes, ocorrência conjunta, essas espécies não são facilmente diferenciadas nos parreirais. A maneira mais fácil de diferenciá-las é com base nas características biológicas, sendo que $\boldsymbol{P}$. persicae apresenta somente uma geração por ano e três estádios ninfais. Já $\boldsymbol{P}$. corni completa de uma a três gerações por ano, apresentando somente dois estádios ninfais (GONZÁLEZ, 1983). As duas

\footnotetext{
${ }^{1}$ Engenheiro Agrônomo, MSc., Fitossanidade, Aluno de Doutorado do Programa de Pós-graduação em Agronomia da Universidade Federal de Pelotas (UFPel). Embrapa Uva e Vinho, Rua Livramento, 515, CP 130, 95700-000, Bento Gonçalves, RS. E-mail: ana@ufpel.tche.br ${ }^{2}$ Engenheiro Agrônomo, MSc., Fitossanidade, AgroCaxias.

${ }^{3}$ Engenheiro Agrônomo, Doutor, Entomologia, Pesquisador Embrapa Uva e Vinho.

${ }^{4}$ Engenheiro Agrônomo, Doutor, Agronomia, Professor Adjunto, Departamento de Fitotecnia, Faculdade de Agronomia Eliseu Maciel (FAEM), UFPel.

${ }^{5}$ Engenheiro Agrônomo, Doutor, Entomologia, Professor Titular, Departamento de Fitossanidade, FAEM, UFPel.
} 
cochonilhas atacam somente brotações novas, ocorrendo de forma localizada nos parreirais. Devido à sucção contínua de seiva, as brotações com a presença do inseto crescem e produzem menos e, dependendo da infestação, podem secar (HICKEL, 1996).

Até o momento, somente $\boldsymbol{P}$. persicae tem sido relatada como praga da videira no Brasil (HICKEL, 1996, SORIA \& DAL CONTE, 2000), sendo considerada praga primária no país e no Chile (GONZÁLEZ, 1983; FOLDI \& SORIA, 1989). No Brasil, encontra-se disseminada principalmente nos vinhedos do Rio Grande do Sul e Santa Catarina associada a uvas de origem americana, destacando-se a Couderc 13 e Seibel (MATOS \& SCHUCK, 1988). Porém, ataques freqüentes também têm sido observados em uvas viníferas.

A importância da cochonilha-parda para a viticultura está sendo ampliada, pois além dos danos diretos, informações oriundas de pesquisas realizadas na Europa evidenciam a associação de $\boldsymbol{P}$. corni com a transmissão do vírus do enrolamento da folha da videira (GLRaV) (BELLI et al., 1994), doença que é considerada uma das mais importantes no Brasil (KUHN \& FAJARDO, 2002). Embora a transmissão de vírus ainda não esteja comprovada para $\boldsymbol{P}$. persicae, em face da similaridade entre as espécies e a importância das viroses para a viticultura brasileira, é importante que os produtores dediquem maior atenção ao controle desse inseto, pelos danos diretos que provoca.

O controle da cochonilha-parda tem sido realizado através da eliminação dos ramos infestados durante a poda e por inimigos naturais de ocorrência espontânea nos parreirais (HICKEL, 1996; SORIA \& DAL CONTE, 2000). Quando a população da praga atinge níveis elevados, geralmente é empregado o controle químico durante o inverno, através da aplicação de inseticidas fosforados associados a óleos vegetais ou minerais (HICKEL, 1996), contudo, a recomendação tem como base a experiência dos produtores, sem uma comprovação cientifica.

O emprego de inseticidas neonicotinóides surgiu como uma nova possibilidade de controle de pragas na cultura da videira. Esses compostos, além de serem de baixa toxicidade ao homem e seletivos aos inimigos naturais, apresentam elevada eficiência contra insetos sugadores da ordem Hemiptera, à qual pertence a cochonilha-parda (LEICHT, 1996).

Este trabalho foi realizado com o objetivo de avaliar a eficiência de alguns inseticidas fosforados e neonicotinóides, via pulverização foliar, visando ao controle de $\boldsymbol{P}$. persicae na cultura da videira.

\section{MATERIAIS E MÉTODOS}

Os experimentos foram conduzidos no período de setembro a novembro de 2001 e de agosto a outubro de 2002, no município de Monte Belo do Sul, RS, empregando a cultivar Isabel plantada em 1978 no espaçamento de $2,0 \mathrm{~m} \times 2,5 \mathrm{~m}$, naturalmente infestada pela cochonilha-parda.

Plantas infestadas pela cochonilha no terceiro ínstar foram identificadas no interior do parreiral, marcando-se um ramo do ano em cada planta. A partir da base de cada ramo do ano, foi realizada uma pré-contagem do número de cochonilhas presentes em $20 \mathrm{~cm}$, com a finalidade de selecionar plantas com infestação semelhante. O delineamento experimental utilizado foi inteiramente casualizado com cinco repetições, sendo cada planta considerada uma repetição.

Os inseticidas e dosagens avaliados em 2001 foram dimetoato (Tiomet $400 \mathrm{CE}, 100 \mathrm{~mL} \mathrm{100L}$ de água ${ }^{-1}$ ), fenitrotion (Sumithion $500 \mathrm{CE}, 150 \mathrm{~mL} \mathrm{100L}$ de água ${ }^{-1}$ ), metidation (Supracid $400 \mathrm{CE}, 100 \mathrm{~mL} \mathrm{100L}$ de água ${ }^{-1}$ ), paratiom metil (Folidol $600 \mathrm{CE}, 100 \mathrm{~mL}$ 100L de água ${ }^{-1}$ ), triclorfon (Dipterex 500 SNAqC, $300 \mathrm{~mL} 100 \mathrm{~L}$ de água ${ }^{-1}$ ) e um tratamento testemunha. Em 2002 foram avaliados imidacloprid (Provado 200 SC, 30, 40 e 50mL 100 de água $^{-1}$ ), tiacloprid (Calypso

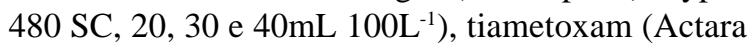
$250 \mathrm{WG}, 20,30$ e $40 \mathrm{~g} 100 \mathrm{~L} \mathrm{de} \mathrm{água}^{-1}$ ) e paratiom metil (Folidol $600 \mathrm{CE}, 100 \mathrm{~mL}$ 100L de água ${ }^{-1}$ ) mantendose um tratamento testemunha (sem aplicação) Os inseticidas foram aplicados em 28 de setembro de 2001 e em 30 de agosto de 2002, pulverizando a parte aérea das plantas até o início do ponto de escorrimento, com auxílio de um pulverizador costal com capacidade de 20 litros, equipado com bico JD 12, num volume de $800 \mathrm{~L} / \mathrm{ha}$. O número de insetos vivos por $20 \mathrm{~cm}$ de ramo foi avaliado aos 7, 14, 21, 28, 35 e 42 dias após a aplicação dos produtos.

Para a análise estatística, foi utilizando o programa Genes (CRUZ, 2001) transformando-se o número de insetos por ramo em $\sqrt{x+0,5}$ sendo as médias comparadas pelo teste de Tukey em nível de $5 \%$ de probabilidade de erro. A eficiência dos inseticidas foi calculada através da fórmula de ABBOTT (1925).

\section{RESULTADOS E DISCUSSÕES}

No experimento de avaliação dos inseticidas fosforados conduzido em 2001 (Tabela 1), somente o tratamento com dimetoato $\left(40 \mathrm{~g} 100 \mathrm{~L}^{-1}\right)$ não 
foi eficiente no controle da cochonilha-parda durante o período de avaliação. A baixa eficiência desse inseticida pode ser devido à menor concentração utilizada, pois HICKEL (1996) relatou com base em experiências de campo uma eficiência de $90 \%$ com a concentração de $50 \mathrm{~g}$ de dimetoato $100 \mathrm{~L}^{-1}$.

$\mathrm{O}$ metidation, paratiom metil e o triclorfon diferiram dos demais inseticidas aos 7 DAT, indicando terem uma ação mais rápida que os demais produtos avaliados (Tabela 1). Na avaliação aos 14 DAT, os inseticidas metidation e paratiom metil apresentaram eficiência de controle superior a $90 \%$, o que se manteve até o final das observações, diferenciandoos dos demais tratamentos. O fenitrotion atingiu $80 \%$ de controle da praga somente aos 28 DAT e o triclorfon a partir dos 42 DAT (Tabela 1).

Na avaliação final, aos 42 DAT, foi possível separar os produtos quanto ao controle da cochonilhaparda em três grupos, destacando-se o metidation e o paratiom metil com controle final de $99 \%$; o fenitrotion e o triclorfon com mortalidade de 83 e $80 \%$, respectivamente, e o dimetoato em posição inferior, reduzindo a população da praga em apenas $43 \%$ (Tabela 1). Os inseticidas metidation e o paratiom metil que apresentaram melhores resultados de controle nesse experimento, também são recomendados para o controle de P. persicae no Chile (GONZÁLEZ, 1983). Entretanto, ressalta-se que o metidation não possui registro para emprego na cultura da videira no Brasil (AGROFIT, 2003).

No experimento conduzido em 2002, a redução da população somente foi verificada aos 21 DAT, destacando-se os inseticidas imidacloprid $(8 \mathrm{~g}$

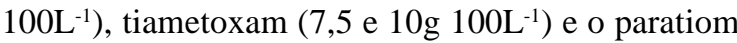
metil. Com relação ao imidacloprid $\left(6,8\right.$ e $\left.10 \mathrm{~g} 100 \mathrm{~L}^{-1}\right)$, tiametoxam $\left(5 ; 7,5\right.$ e $\left.10 \mathrm{~g} 100 \mathrm{~L}^{-1}\right)$ e paratiom metil, somente aos 35 DAT ocorreu controle superior a $80 \%$, sendo que o tiametoxam demonstrou maior rapidez de ação em relação ao imidacloprid (Tabela 2).

Na avaliação final, aos 42 DAT, também se distinguiram dois grupos, em que o imidacloprid e o tiametoxam foram equivalentes ao inseticida padrão paratiom metil com eficiência superior a $80 \%$, enquanto que o tiacloprid proporcionou mortalidade inferior (Tabela 2).

O controle da cochonilha-parda na cultura da videira tem sido realizado principalmente com inseticidas fosforados, com destaque para o paratiom metil. Entretanto, esse inseticida apresenta restrições de uso, principalmente levando-se em consideração a toxicidade que apresenta. Os resultados obtidos com os neonicotinóides imidacloprid e tiametoxam demonstram ser novas 


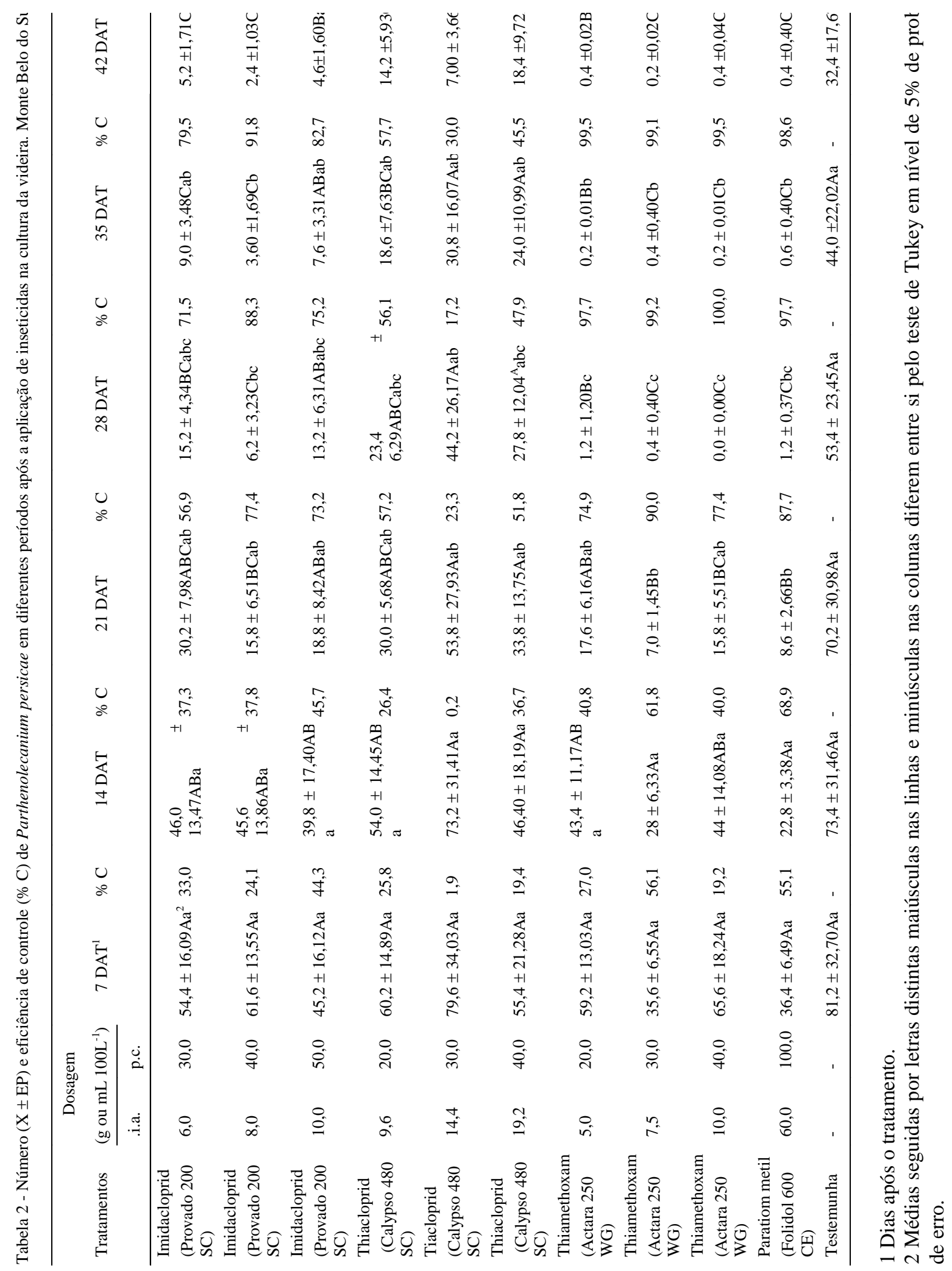


alternativas para o manejo do inseto na cultura da videira.

No período de condução do experimento, foi observada uma redução do número de insetos presentes nos ramos das parcelas testemunha (Tabelas 1 e 2). Tal fato é atribuído à competição intraespecífica, além do ataque de inimigos naturais, fato que necessita ser mais bem avaliado visando ao incremento do controle biológico natural.

Neste trabalho, os inseticidas avaliados foram aplicados sem a adição de óleos, conforme preconizado por HICKEL (1996). O efeito dos produtos associados a adjuvantes, bem como o efeito destes de forma isolada ainda necessitam ser avaliados visando ao controle da praga na cultura da videira.

\section{CONCLUSÕES}

Os inseticidas Sumithion $500 \mathrm{CE}, 150 \mathrm{~mL}$

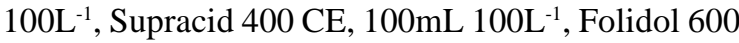

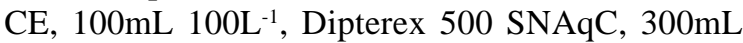

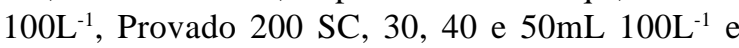
Actara $250 \mathrm{WG}, 20,30$ e $40 \mathrm{~g} 100 \mathrm{~L}^{-1}$ aplicados visando às ninfas de terceiro ínstar, são eficientes no controle de $\boldsymbol{P}$. persicae na cultura da videira.

Os inseticidas Tiomet $400 \mathrm{CE}, 100 \mathrm{~mL}$ $100 \mathrm{~L}^{-1}$ e Calypso 480 SC não são eficientes no controle da cochonilha-parda na cultura da videira.

\section{AGRADECIMENTOS}

Ao Assistente de Pesquisa da Embrapa Uva e Vinho Léo Antônio Carollo e ao Bolsista de Estágio Técnico da FAPERGS Odimar Zanardi pelo apoio na condução dos experimentos.

\section{REFERÊNCIAS BIBLIOGRÁFICAS}

ABBOTT, W.S. Amethod of computing the effectiveness of an insecticide. Journal of Economic Entomology, v.18, n.1, p.265-267, 1925.

AGROFIT: Ministério da Agricultura Pecuária e Abastecimento. Capturado em Mar, 2003. Online. Disponível na Internet http:// www.agricultura.gov.br/agrofit.

BELLI, G. et al. Transmission of grapevine leafroll associated closterovirus by the scale insect Pulvinaria vitis $\mathbf{L}$. Rivista di Patologia Vegetale, v.4, p.105-108, 1994.

CRUZ, C.D. Programa genes: aplicativo computacional em genética e estatística. Viçosa : UFV, 2001. 648p.

FOLDI, I.; SORIA, S.J. Les cochonilles nuisibles a la vigne en Amérique du Sud (Homoptera: Coccoidea). Annales de la Societè Entomologique de France, n.25, p.411-430, 1989.

GONZALEZ, R.H. Manejo de plagas de la vid. Universidad de Chile. Facultad de Ciencias Agrarias, Veterinarias y Forestales. Publicaciones en Ciencias Agrícolas, n.13, 132p, 1983.

HICKEL, E.R. Pragas da videira e seu controle no Estado de Santa Catarina. Florianópolis : EPAGRI, 1996. 52p.

KUHN, G.B.; FAJARDO, T.V.M. Viroses da videira no Brasil. In: CURSO DE CAPACITAÇÃO TÉCNICA EM VITICULTURA Módulo 3, 2002, Bento Gonçalves : Embrapa Uva e Vinho, 2002. 44p.

LEICHT, W. Imidacloprid - a chloronicotinyl insecticide biological activity and agricultural significance. Pflanzenschutz-Nachrichten Bayer, Netherlands, v.49, n.3, p.71-84, 1996.

MATOS, C.S.; SCHUCK, E. Controle de pragas na videira. Agropecuária Catarinense, Florianópolis, v.1, n.2, p.12-14, 1988.

PELLIZZARI, G. Soft scale insects - their biology, natural enemies and control. N.i.:Y. Ben-Dov and C.J.Hodgson, 1997, p.323-331.

SORIA, S.J.; DAL CONTE, A.F. Bioecologia e controle das pragas da videira no Brasil. Entomologia y Vectores, Rio de Janeiro, v.7, n.1, p.73-102, 2000. 